\title{
Maaike Koffeman, Entre Classicisme et Modernité: La Nouvelle Revue Française dans le champ littéraire de la Belle Époque
}

\section{Emanuele Kanceff}

\section{(2) OpenEdition \\ Journals}

Edizione digitale

URL: https://journals.openedition.org/studifrancesi/38192

DOI: $10.4000 /$ studifrancesi.38192

ISSN: 2421-5856

\section{Editore}

Rosenberg \& Sellier

\section{Edizione cartacea}

Data di pubblicazione: 15 décembre 2004

Paginazione: 642-643

ISSN: 0039-2944

\section{Notizia bibliografica digitale}

Emanuele Kanceff, «Maaike Koffeman, Entre Classicisme et Modernité: La Nouvelle Revue Française dans le champ littéraire de la Belle Époque», Studi Francesi [Online], 144 (XLVIII | III) | 2004, online dal 30 novembre 2015, consultato il 08 mai 2021. URL: http://journals.openedition.org/studifrancesi/38192 ; DOI: https://doi.org/10.4000/studifrancesi.38192

Questo documento è stato generato automaticamente il 8 mai 2021.

\section{cc) $($ ) $\ominus$}

Studi Francesi è distribuita con Licenza Creative Commons Attribuzione - Non commerciale - Non opere derivate 4.0 Internazionale. 


\title{
Maaike Koffeman, Entre Classicisme et Modernité: La Nouvelle Revue Française dans le champ littéraire de la Belle Époque
}

\author{
Emanuele Kanceff
}

\section{NOTIZIA}

MAAIKE KOFFEMAN, Entre Classicisme et Modernité: La Nouvelle Revue Française dans le champ littéraire de la Belle Époque, Amsterdam-New York, Rodopi, 2003 (Coll. «Faux Titre», 239. Études de langue et littérature française publiées sous la direction de Keith BUSBY, M. J. FREemAN, Sjef houpPermans, Paul PelckMANS et Co Vet), pp. 291.

1 Lo studioso che si interessi alla storia de «La Nouvelle Revue française» non mancherà di essere colpito dall'immagine mitica di cui questa rivista letteraria gode in Francia. Lungo tutto il Novecento abbondano testimonianze del prestigio intellettuale di questa rivista, sicché si comprende una battuta dell'ambasciatore tedesco a Parigi Otto Abetz che in un giorno del 1940 avrebbe detto: «Il y a trois forces en France: le communisme, la haute banque et $L a N R F$ ». Questo episodio è molto probabilmente inventato ma il fatto che lo si citi ad ogni piè sospinto è molto eloquente circa la reputazione leggendaria della rivista.

2 La «NRF» che François Mauriac considerava la bussola della letteratura francese fra le due guerre godette in Francia di un prestigio incomparabile. L'autore di questo libro risale alle origini di questa leggenda conducendo un'analisi nello stesso tempo storica, letteraria e sociologica dei primi anni della rivista e mostrando che le ragioni principali del suo successo si realizzano già prima della Grande Guerra. L'ascesa incontenibile del periodico non dipende soltanto dalla qualità dei testi che pubblica ma anche dalle 
strategie messe in opera per conquistare una posizione dominante nella letteratura della Belle Époque.

3 L'analisi interna dei numeri della rivista dimostra che c'è uno stretto rapporto tra programma artistico e posizioni letterarie. Il classicismo moderato della «NRF» le permette di riunire attorno a sé i migliori scrittori del suo tempo e di dare un contributo importante al rinnovamento del romanzo francese. Essa non manca di una risonanza internazionale; anzi con il concetto di modernismo contribuisce a preparare la grande trasformazione del romanzo europeo. 